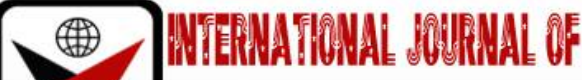

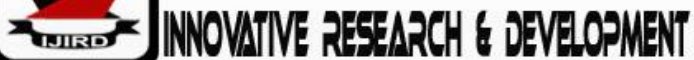

ISSN 2278 - 0211 (Online)

\section{Impact of Physical Activity on Wellness of Students in Private Secondary Schools in Osun State, Nigeria}

\begin{tabular}{|c|}
\hline Dr. Oyedele, Akinsanmi Opeoluwa \\
Principal Lecturer, Department of Physical and Health Education, \\
Osun State College of Education, Ila-Orangun, Osun State, Nigeria \\
Dr. Adisa, Olawumi \\
Principal Lecturer, Department of Physical and Health Education, \\
Osun State College of Education, Ila-Orangun, Osun State, Nigeria \\
Dr. Oloyede, Oyetunde Abiodun \\
Principal Lecturer, Department of Physical And Health Education, \\
Osun State College of Education, Ila-Orangun, Osun State, Nigeria
\end{tabular}

\begin{abstract}
:
Sport is an integral part of the formal system of educational process essential for the total development of an individual. In spite of the benefits of participation in physical activities in relation to wellness, it was observed that most private schools in Osun State did not build and maintain sports facilities. The study therefore, examined impact of physical activity on wellness of students in private secondary schools in Osun State. The study adopted descriptive survey design. The respondents were selected from fifteen private schools in Osun State. Purposive, disproportionate stratified and simple random sampling techniques were adopted in selecting twenty (20) students per school; with a total of 300 respondents. Questionnaires were used to collect data. Data were analysed using inferential statistics of PPMC and multiple linear regressions. The findings revealed that availability of sports facilities had positive correlation with physical activity participation among students of private Secondary Schools in Osun State. Physical activities involving ball games of football, basketball, volleyball and handball jointly had impact on wellness of respondents. Football and handball had relative impact on wellness of students; while basketball and volleyball did not. Physical activities involving racket games of tennis, badminton, squash and table tennis jointly had impact on wellness of students. Tennis, badminton and table tennis had relative impact; while squash did not. It was concluded that, participation in ball and racket games as physical activities jointly had impact on wellness of respondents. Physical activities involving football, handball, tennis, badminton and table tennis had relative impact. It was recommended among others that; the Ministry of Education in Osun State should legislate that all the schools make adequate provision for sports facilities in schools.
\end{abstract}

Keywords: Physical activity, wellness of students and private secondary schools

\section{Introduction}

\subsection{Background to the Study}

Sport is an integral part of the formal system of educational process. It is essential for the total development of an individual. Sport, therefore is part of the School curriculum from Nursery School to the university level. Ofili (2010) described sports as all organized physical activities engaged in outdoors or indoors, done in a special area for pleasure or competitive in nature under specific rules and regulations. Sports bring refreshingly satisfying experience during and after participation to both old and young. Regular participation in sports and physical activities offer tremendous physical, social, emotional, mental and economic benefits to individuals and groups. Since children are full of activities, because of the volume of energy in them which must be expended, children gain a lot in participating in sports and physical activities.

Studies have shown that sports and exercises promote physical fitness, build and maintain healthy bones, muscles, joints and vital organs of the body. Exercise can help people feel better and their lives too, reduce anxiety and improve mood. Evidence is also building to show that physical activity is associated with substantially reduced risks of mental illnesses and conditions. The benefits of physical activity in the treatment of depression (National Institute of Clinical Excellence, 2004) and improvement in selective aspects of cognitive function in older adults are becoming increasingly well established (Angevaren, Aufdemkampe, Verhaar, Aleman, \& Vanhees, 2008). Sports can promote the spirit of social interaction, cooperation, friendship and foster desirable social behavior like loyalty, honesty, fair play, trust, build selfdiscipline, respect for others and constituted authority among individuals and groups. Sports carry the capability to foster peace and unity among people of different backgrounds and race. Sports have been used as a strategic weapon for peacebuilding, even in warring Nations like Liberia. It contributes to psychological wellbeing by reducing anxiety and 
depression; enhance self-esteem, tangible experiences of competencies and successes as well as increased self-confidence and sense of accomplishment.

In the same vein, studies also revealed that physical activity is associated with mental health and wellness of individuals. It was further established that regular activity and improved fitness contribute to psychological well-being (Biddle \& Mutrie, 2008; Biddle, Fox \& Boutcher, 2001). They further revealed that, there has also being growing interest in the benefits of physical activity for mental health and a strong evidence base shows that regular activity and improved fitness increases psychological well-being. In the same vein, Case, Fertig and Paxon (2005) revealed that students' health is associated with low educational level, social, economic and behavioral problems. Furthermore, Yu Pan, Chia- Hua Chu, Chia- Liang Tsai, Sha- Yu Lo, Yun- Wen Cheng and Yu-Jen Liu (2016) in their study assessed the positive direct effects of engaging in regular physical activity particularly apparent in the prevention of several chronic diseases, including: cardiovascular disease, diabetes, cancer, hypertension, obesity, depression and osteoporosis. Their study assessed the effects of a 12-week table tennis exercise on motor skills, social behaviors, and executive functions in children with attention deficit hyperactivity disorder (ADHD). The study revealed that, "the racket-sport intervention is valuable in promoting motor skills, social behaviors, and executive functions and should be included within the standard-of-care treatment for children with ADHD”. Nabofa and Eboh (2011) posited that leading a physically active lifestyle can help prevent diseases and positively contribute to health and wellbeing of all people regardless of age, race, ethnicity, gender, sexual orientation, disability status, income, educational level, or geographical location. The World Health Organization [WHO] (2004) revealed that an average individual need to live a physically active life to ensure optimal health and wellness. Consequently, it was recommended that school children should do daily exercises and physical activities for at least 60 minutes so as to achieve an adequate amount of physical fitness and wellness. This therefore, necessitated construction and maintenance of adequate sports facility as the platform to achieve this.

School sports are capable of eliciting wellness benefits to the school, students / pupils and society as a whole. So, school sporting activities have several derived advantages that can impact on the health and educational development of school children. According to Watson (2010), wellness benefits of school sports include raising money from community resources, bringing students together for common cause, create role models, promote social control, teaching societal/ school values, stopping from questioning the rules, draining energy and so diverts youthful energy and attention positively. It was further established that school sports bring to students, fame, gifts / money, social popularity, character improvement, adjustment to failure as well as better reasoning that should naturally lead to higher academic performance. Fahay, Insell, \& Roth (2003) stated that school sports are capable of improving all the dimensions of wellness which have been identified to include physical wellness, emotional wellness, intellectual wellness, spiritual wellness, social wellness and environmental or planetary wellness. Good nutrition, sports and exercise brings wellness and wellbeing and thus physical fitness to school children.

Physical activity helps children's cognitive development, development of the body organs and protection against deficiency. A positive relationship of physical activity and academic performance has been explored through several studies conducted in the USA by the California Department of Education; Dwyer, Sallis, Blizzard, Lazarus, \& Dean (2001); Dwyer et al. (1983); Linder (1999); Linder (2002); Shephard (1997); Tremblay et al. (2000); and others. These studies support one another in suggesting that when a substantial amount of school time is dedicated to physical activity, academic performance meets and may even exceed that of students not receiving additional physical activity (Shephard, 1997). Physical activity and sports play great roles in the developmental growth of children and the capacity for enhancing body systems to function at peak level could be very incredible. When children are exposed to physical activity and sports early in life, their cognitive performance is increased over their colleagues that do not engage in physical activity and sports. Physical activity and sports, when regulated will also compliment wellness of school children and even adults.

Weikart's concern was that children are having fewer opportunities to be physically active and develop basic motor skills that will enhance children academically. In another study by Mitchell, findings revealed that there is "the relationship between rhythmic competency and academic performance in first grade children" (1994). The findings supported a link between academic achievement and the motor skills of maintaining a steady beat. Also motivated by Phyllis Weikart, are Kuhlman \& Schweinhart, who reported in their discussions that children's timing has been found to be positively related to children's overall school achievement, as well as mathematics and reading achievement (1999). According to Leslee J. S, and Debby M (2001), in their study on, "Does physical activity influence academic performance?" concludes that; enhanced brain function, energy levels, body builds/perceptions, self-esteem, and behavior have been attributed to physical activity and to improved academic performance. Regulated physical activity and sports in schools will build body physiological and psychological growth and consequently enhance wellness of school children. Furthermore, a significant body of research has demonstrated, that student health predicts low educational level, social and economic inequalities, and behaviour problems experienced into adulthood (Case, Fertig, \& Paxon, 2005; Needham et al., 2004; Palloni, 2006). There is an assumption that improvement in nutrition and physical fitness will have a direct and positive influence on academic performance. Yet, the relationship between physical fitness and academic performance is a complex one that has multiple, alternative explanations. Therefore, the provision and standardization of sports facility in private schools is not negotiable because of the numerous benefits that children would enjoy at the school level.

On the contrary, there is proliferation of "a one block of rooms' international schools" in Osun State. Meanwhile, this contravenes "the United Nations Convention on the Rights of the Child (1989) Article 29.1. The article stated that, "the education of the child shall be directed to the development of the child's personality, talents, mental and physical abilities to their fullest potential". In spite of the benefits that are attached to participation in physical activities in relation to wellness, it was observed that most schools, especially private schools in Osun State did not build and maintain sports facilities for sporting activities for school children. Non-compliance of most private schools to standard sports facility 
development may be a foundation for athlete's poor performance in international sports engagements today. Additionally, there is a rise in childhood diseases and cases of child obesity among school children. The study therefore, examined impact of physical activity on wellness of students in private secondary schools in Osun State.

\subsection{Statement of the Problem}

The potential for physical activity and fitness to improve cognitive function, learning and academic achievement in children has received attention by researchers and policy makers in developed nations. There seems to be a disconnect between founders of private secondary schools and government criteria for provision of sports facilities for physical activity, fitness and sports development of children in private schools in Osun State. It has been ascertained that physical activity helps children's cognitive development, development of the body organs and protection against deficiency. However, there is proliferation of "a one - block of rooms' international schools" in Osun State; which has contravened "the United Nations Convention on the Rights of the Child (1989) Article 29.1. In spite of the benefits that are attached to participation in physical activities in relation to wellness, it was observed that most schools, especially private schools in Osun State do not see the need to build and maintain sports facilities for sporting activities for children. Non-compliance of most private schools to standard sports facility development may be a foundation for athlete's poor performance in international sports engagements today. Additionally, there is a rise in childhood diseases and cases of child obesity among school children. The study therefore, examined impact of physical activity on wellness of students in private secondary schools in Osun State.

\subsection{Main Objective}

The main objective of the study is to examine the impact of physical activity participation on wellness of students in private secondary schools in Osun State

\subsection{Specific Objectives}

The following specific objectives were focused on:

- To examine the level of relationship between availability of sports facilities and physical activity participation among students of private Secondary Schools in Osun State.

- To establish the joint impact of physical activities involving ball and racket games on wellness of students of private secondary schools in Osun State.

- To establish the relative impact of physical activities involving ball and racket games on wellness of students of private secondary schools in Osun State.

\subsection{Research Question}

The below research question was answered:

- What is the level of relationship between availability of sports facilities and physical activity participation among students of private Secondary Schools in Osun State?

\subsection{Hypotheses}

The following hypotheses were tested:

- There will be no significant joint impact of physical activities involving ball games (football, basketball, volleyball and handball) on wellness of students of private secondary schools in Osun State.

- There will be no significant relative impact of physical activities involving ball games (football, basketball, volleyball and handball) on wellness of students of private secondary schools in Osun State

- There will be no significant joint impact of physical activities involving racket games (tennis, badminton, squash and table tennis) on wellness of students of private secondary schools in Osun State.

- There will be no significant relative impact of physical activities involving racket games (tennis, badminton, squash and table tennis) on wellness of students of private secondary schools in Osun State

\section{Methodology}

\subsection{Research Design}

A descriptive survey design of correlational type was used in the study. This design was considered suitable due to its merits in describing the existing issues in relation to the tested variables.

\subsection{Sample and Sampling Technique}

The population involved the students of private secondary schools in Osun State. Multi-stage sampling procedure was used to select 300 respondents in the study. The sampling procedure includes purposive, disproportionate stratified and simple random sampling techniques. Purposive sampling technique was used to consider the three senatorial districts as the study area. Simple random sampling technique of fish bowl was used to select five Local Government Areas from each of the three senatorial districts, making a total of fifteen (15) Local Government Areas. The same technique was used to choose ten (10) schools from each of the Local Government Areas, making a total of thirty (30) schools. Disproportionate stratified sampling technique was used to consider the selection of ten (10) respondents each from the chosen schools respectively. Simple random sampling technique was used to select the earlier predetermined ten (10) respondents from each of the selected schools. 


\subsection{Instrument}

The instrument for data collection in the study was a self developed and validated questionnaire labeled as; Physical Activity and Wellness of Students in Private Secondary Schools Questionnaire (PAWSPSSQ). The questionnaire was divided into three sections, namely, A, B and C. Section A covered demographic information of the respondents, section B involved Physical Activity (PAS), while section C consist Wellness of Students Scale (WSS). The demographic information of the respondents covered in section A include; sex and age. Section B was used to gather information on physical activity; while section $C$ was used to elicit information on wellness of students. The responses in sections B and C were constructed in a 4-point modified Likert format of Strongly Agree (SA), Agree (A), Disagree (D) and Strongly Disagree (SD). A Cronbach alpha method was also used to test the internal consistency of the questionnaire, which yielded a reliability of 0.71 .

\subsection{Statistical Analysis}

The filled copies of questionnaire were collated, coded and analysed using both descriptive and inferential statistics. Data were analyzed using the Statistical Package for Social Sciences program (SPSS), version 20. Descriptive statistics was used to analyze the demographic variables, inferential statistics of Pearson Product Moment Correlation (PPMC) was used to analyze research question, while multiple linear regression was used to test hypotheses at 0.05 alpha level.

\section{Results of the Study}

\begin{tabular}{|c|c|c|c|}
\hline S/n & Demographic Variables & Frequency & Percent (\%) \\
\hline \multirow{2}{*}{.. } & Sex: & & 48.0 \\
& Male & 143 & 52.0 \\
\cline { 2 - 4 } & Female & 157 & 100.0 \\
\hline \multirow{2}{*}{2.} & Total & 300 & 2.0 \\
& Age: & 6 & 36.0 \\
& 10 years and below & 108 & 62.0 \\
\cline { 2 - 4 } & $11-15$ years & 186 & 100.0 \\
\hline
\end{tabular}

Table 1: Distribution of the Students by Demographic Characteristics

Table 1 indicated that, 143 (48.0\%) respondents are male, while 157 (52.0\%) are female. This means that most of the respondents are female. In addition, 6 (2.0\%) respondents were 10 years and below, 108 (36.0\%) were 11-15 years, while $186(62.0 \%)$ were 16-20 years. This means that most of the respondents were 16-20 years.

\subsection{Research Question}

The below research question was answered:

- $\quad$ Research Question 1: What is the level of relationship between availability of sports facilities and physical activity participation among students of private Secondary Schools in Osun State?

\begin{tabular}{|c|c|c|c|c|}
\hline Variables & Physical Activity & $\begin{array}{c}\text { Availability of Sports } \\
\text { Facilities }\end{array}$ & Nig. \\
\hline Physical activity & 1 & $.472^{* *}$ & & \\
\cline { 1 - 3 } $\begin{array}{c}\text { Availability of sports } \\
\text { facilities }\end{array}$ & $.472^{* *}$ & 1 & 300 & .000 \\
\hline $\begin{array}{c}\text { Mean } \\
\text { Standard Dev }\end{array}$ & 4.2167 & 4.4967 & & \\
\hline
\end{tabular}

Table 2: Correlation Analysis on Relationship between Availability of Sports

Facilities and Physical Activity Participation

**Correlation Is Significant At 0.05 (2-Tailed)

Table 2 showed that there was a significant and positive correlation between availability of sports facilities and physical activity participation among students of private Secondary Schools in Osun State ( $\mathrm{r}=0.472, \mathrm{~N}=300 ; p<0.05)$. This means that, an increased influence of availability of sports facilities could increase physical activity participation among students of private secondary schools in Osun State. Sang Ah Lee, Yeong Jun Ju, Joo Eun Lee, In Sun Hyun, Jin Young Nam, Kyu-Tae Han and Eun-Cheol Park (2016) posited that sports facility accessibility is considerably associated with the amount of physical activity an individual participates in. Thornton, Pearce, Kavanagh (2011) buttressed the above, stated that easy access to sports facility may act as a motivator to encourage an individual to participate in physical activity. Sang Ah Lee, et al (2016) concluded that the accessibility of sports facilities is associated with physical activity. "Therefore, it is crucial to consider the accessibility of sports facilities when promoting an environment conducive to physical activity or designing programmes for enhancing physical activity". Sports facilities are like what laboratory is to science students. 
Sports facilities remain key factors to encourage school children to participate in physical activity to have an all-round development and to attain wellness.

\subsection{Hypotheses}

The following hypotheses were tested in this study:

- Hypothesis 1: There will be no significant joint impact of physical activities involving ball games (football, basketball, volleyball and handball) on wellness of students of private secondary schools in Osun State

\begin{tabular}{|c|c|c|c|c|c|c|}
\hline \multicolumn{7}{|c|}{$\begin{array}{c}\mathbf{R}=.803 \\
\mathbf{R}^{2}=.646 \\
\text { Adj. } \mathbf{R}^{2}=.641 \\
\text { Std. Error=1.55517 }\end{array}$} \\
\hline Model & $\begin{array}{c}\text { Sum of } \\
\text { Squares }\end{array}$ & Df & Mean Square & F & $\begin{array}{c}\text { Sig. } \\
\text { (p value) }\end{array}$ & Remark \\
\hline Regression & 1299.194 & 4 & 324.799 & 134.295 & .000 & Significant \\
Residual & 713.473 & 295 & 2.419 & & & \\
Total & 2012.667 & 299 & & & & \\
\hline
\end{tabular}

Table 3: Summary of Multiple Regressions about Joint Impact of Physical Activities Involving Ball Games

As indicated in table 3, it was found that the linear combination of physical activities involving ball games (football, basketball, volleyball and handball) was tested significant $\left(\mathrm{F}_{(4,295)}=134.295, p<0.05\right)$ on wellness of students of private secondary schools in Osun State. The result yielded a coefficient of multiple regression of R=0.803 and multiple Rsquare of 0.646 . The result also revealed that adjusted $\mathrm{R}^{2}=0.641$; indicating that about $64.1 \%$ of variance was accounted for by the independent variables. The null hypothesis was therefore rejected. This implied that physical activities involving ball games of football, basketball, volleyball and handball jointly had impact on wellness of students of private secondary schools in Osun State. To buttress the above, it was established that regular activity and improved fitness contribute to psychological well-being (Biddle \& Mutrie, 2008; Biddle, Fox \& Boutcher, 2001). They further revealed that, there has also being growing interest in the benefits of physical activity for mental health and a strong evidence base shows that regular activity and improved fitness increases psychological well-being. In the same vein, Case, Fertig and Paxon (2005) revealed that students' health is associated with low educational level, social and economic and behaviour problems.

- Hypothesis 2: There will be no significant relative impact of physical activities involving ball games (football, basketball, volleyball and handball) on wellness of students of private secondary schools in Osun State.

\begin{tabular}{|c|c|c|c|c|c|c|}
\hline \multirow[t]{2}{*}{ Variables } & \multicolumn{2}{|c|}{$\begin{array}{c}\text { Unstandardized } \\
\text { Coefficients }\end{array}$} & \multirow{2}{*}{$\begin{array}{c}\text { Standardized } \\
\text { Coefficients } \\
\beta\end{array}$} & \multirow[t]{2}{*}{$\mathbf{T}$} & \multirow[t]{2}{*}{$\begin{array}{c}\text { Sig. } \\
(p \text { value })\end{array}$} & \multirow[t]{2}{*}{ Remark } \\
\hline & B & Std. Error & & & & \\
\hline (Constant) & .442 & .304 & & 1.454 & .147 & \\
\hline Football & 1.003 & .067 & .724 & 14.876 & .000 & Significant \\
\hline Basketball & .097 & .078 & .071 & 1.247 & .213 & Not Sig. \\
\hline Volleyball & .009 & .080 & .006 & .110 & .912 & Not Sig. \\
\hline Handball & .145 & .050 & .104 & 2.888 & .004 & Significant \\
\hline
\end{tabular}

Table 4: Summary of Regression about Relative Prediction of Physical Activities Involving Ball Games

Table 4 showed physical activities involving ball games, the unstandardized regression weight ( $($ ), the standardized error of estimate (SEß), the standardized coefficient, the t-ratio and the level at which the t-ratio was significant. As indicated in the table, football $(\beta=0.724, t=14.876, p<0.05)$ and handball $(\beta=0.104, t=2.888, p<0.05)$ were tested significant on wellness of students of private secondary schools in Osun State; while basketball $(ß=0.071, t=1.247$, $p>0.05)$ and volleyball $(\beta=0.006, t=0.110, p>0.05)$ did not. The null hypothesis which stated that there will be no significant relative impact of physical activities involving ball games of football and handball on wellness of students of private secondary schools in Osun State was therefore rejected. This means that physical activities involving ball games of football and handball had significant impact on wellness of students of private secondary schools in Osun State. Nabofa and Eboh (2011) posited that leading a physically active lifestyle can help prevent diseases and positively contribute to health and wellbeing of all people regardless of age, race, ethnicity, gender, sexual orientation, disability status, income, educational level, or geographical location. The World Health Organization [WHO] (2004) revealed that an average individual need to live a physically active life to ensure optimal health and wellness. Consequently, it was recommended that school children should do daily exercises and physical activities for at least 60 minutes so as to achieve an adequate amount of physical fitness and wellness. This therefore necessitated construction and maintenance of adequate sports facility as the platform to achieve this.

- Hypothesis 3: There will be no significant joint impact of physical activities involving racket games (tennis, badminton, squash and table tennis) on wellness of students of private secondary schools in Osun State 


\begin{tabular}{|c|c|c|c|c|c|c|}
\hline \multicolumn{7}{|c|}{$\begin{array}{c}\text { R=.536 } \\
\mathbf{R}^{2}=.287 \\
\text { Adj. } \mathbf{R}^{2}=\mathbf{2 7 7} \\
\text { Std. Error=2.20543 }\end{array}$} \\
\hline Model & $\begin{array}{c}\text { Sum of } \\
\text { Squares }\end{array}$ & Df & Mean Square & F & $\begin{array}{c}\text { Sig. } \\
\text { (p value) }\end{array}$ & Remark \\
\hline Regression & 577.811 & 4 & 144.453 & 29.699 & .000 & Significant \\
Residual & 1434.856 & 295 & 4.864 & & \\
Total & 2012.667 & 299 & & & \\
\hline
\end{tabular}

As indicated in table 5, it was found that the linear combination of physical activities involving racket games (tennis, badminton, squash and table tennis) was tested significant $\left(F_{(4,295)}=29.699, p<0.05\right)$ on wellness of students of private secondary schools in Osun State. The result yielded a coefficient of multiple regression of R=0.536 and multiple Rsquare of 0.287 . The result also revealed that adjusted $\mathrm{R}^{2}=0.277$; indicating that about $27.7 \%$ of variance was accounted for by the independent variables. The null hypothesis was therefore rejected. This implied that physical activities involving ball games of tennis, badminton, squash and table tennis jointly had impact on wellness of students of private secondary schools in Osun State. Supporting the above, Yu Pan, Chia- Hua Chu, Chia- Liang Tsai, Sha- Yu Lo, Yun- Wen Cheng and YuJen Liu (2016) in their study assessed the effects of a 12-week table tennis exercise on motor skills, social behaviors, and executive functions in children with attention deficit hyperactivity disorder (ADHD). The findings revealed that "the racket-sport intervention is valuable in promoting motor skills, social behaviors, and executive functions and should be included within the standard-of-care treatment for children with ADHD". To further buttressed the above, Ming-De Chan, Hsien-Yu Tsai, Chin-Chung Wang and Yee-Pay Wuang (2005) stated that "Children may benefit more from exercise because their brain structures are developing".

- Hypothesis 4: There will be no significant relative impact of physical activities involving racket games (tennis, badminton, squash and table tennis) on wellness of students of private secondary schools in Osun State

\begin{tabular}{|c|c|c|c|c|c|c|}
\hline \multirow[t]{2}{*}{ Variables } & \multicolumn{2}{|c|}{$\begin{array}{l}\text { Unstandardized } \\
\text { Coefficients }\end{array}$} & \multirow{2}{*}{$\begin{array}{c}\text { Standardized } \\
\text { Coefficients } \\
B\end{array}$} & \multirow[t]{2}{*}{$\mathbf{T}$} & \multirow[t]{2}{*}{$\begin{array}{c}\text { Sig. } \\
(p \text { value })\end{array}$} & \multirow[t]{2}{*}{ Remark } \\
\hline & B & $\begin{array}{c}\text { Std. } \\
\text { Error }\end{array}$ & & & & \\
\hline (Constant) & 1.412 & .423 & & 3.339 & .001 & \\
\hline Tennis & .289 & .147 & .158 & 1.966 & .050 & Significant \\
\hline Badminton & .251 & .117 & .152 & 2.146 & .033 & Significant \\
\hline Squash & .110 & .210 & .050 & .523 & .601 & Not Sig. \\
\hline Table tennis & .505 & .178 & .247 & 2.836 & .005 & Significant \\
\hline
\end{tabular}

Table 6: Summary of Regression about Relative Prediction of Physical Activities Involving Racket Games

Table 6 showed physical activities involving ball games, the unstandardized regression weight (ß), the standardized error of estimate (SEß), the standardized coefficient, the t-ratio and the level at which the t-ratio was significant. As indicated in the table, tennis $(B=0.158, \mathrm{t}=1.966, p<0.05)$, badminton $(\beta=0.152, \mathrm{t}=2.146, p<0.05)$ and table tennis $(ß=0.247, t=2.836, p<0.05)$ were tested significant on wellness of students of private secondary schools in Osun State; while squash $(\beta=0.050, t=0.523, p>0.05)$ did not. The null hypothesis which stated that there will be no significant relative impact of physical activities involving racket games of tennis, badminton and table tennis on wellness of students of private secondary schools in Osun State was therefore rejected. To support the findings, best (2010) and Golubovic, Maksimovic, Golubovic, Glumbic (2012) revealed that, different dimensions of cognitive performance, such as processing speed, planning and control strategies, and working memory, could be improved by physical exercise and regular physical activity. "As well, exercise-centered interventions have been proven to be advantageous in enhancing visual-perceptual functions in children with various developmental disabilities" Deutsch, Borbely, Filler, Huhn, Guarrera-Bowlby (2008) and Wuan, Chiang, Su, Wang (2011). To further support this study, Rodrigues, Vickers, Williams (2002), also stated that, Table tennis is a racket sport that requires functional pairing between perceptual and action modalities under different spatial and temporal demands. In a study by Table Tennis has been also applied in individuals with disabilities, and studies have lent support to its effectiveness in enhancing motor proficiencies Lin (2012), physiological outcome (Rogers, Furler, Brinks, Darrah, 2008), praxis skills (Tsai, 2009), and psychosocial status (Taylor, Maddison, Pfaeffl, Rawstorn, Gant, Kerse, 2012).

\section{Discussion of Findings}

The finding of the study revealed that there was a significant and positive correlation between availability of sports facilities and physical activity participation among students of private Secondary Schools in Osun State. This means that, an increased influence of availability of sports facilities could increase physical activity participation among students of private secondary schools in Osun State. The outcome of this study was in line with the finding of Biddle, Fox \& Boutcher (2001) that physical activity is associated with mental health of individuals.

The finding of the study also revealed that the linear combination of physical activities involving ball games (football, basketball, volleyball and handball) was tested significant on wellness of students of private secondary schools in 
Osun State. It implied that physical activities involving ball games of football, basketball, volleyball and handball jointly had impact on wellness of students of private secondary schools in Osun State. This means that, the participation of the students in ball games like football, basketball, volleyball and handball jointly contributed to their wellness. The outcome of this study was in line with the finding of Biddle \& Mutrie (2008) that regular activity and improved fitness contributes to psychological well-being.

It was further revealed that football and handball were tested significant on wellness of students of private secondary schools in Osun State; while basketball and volleyball did not. This means that physical activities involving football and handball had relative and significant impact on wellness of students of private secondary schools in Osun State. It indicated that physical activities involving football and handball independently had significant impact on wellness of the students. The outcome of this study was in line with the finding of Case, Fertig and Paxon (2005) that students' health is associated with low educational level, social and economic and behaviour problems.

The finding of the study further revealed the linear combination of physical activities involving racket games (tennis, badminton, squash and table tennis) was tested significant on wellness of students of private secondary schools in Osun State. It implied that physical activities involving racket games of tennis, badminton, squash and table tennis jointly had impact on wellness of students of private secondary schools in Osun State. This means that, the participation of the students in racket games like tennis, badminton, squash and table tennis jointly contributed to their wellness. The outcome of this study was in line with the finding of Biddle \& Mutrie (2008) that regular activity and improved fitness contributes to psychological well-being.

It was further revealed that tennis; badminton and table tennis were tested significant on wellness of students of private secondary schools in Osun State; while squash did not. This means that physical activities involving tennis, badminton and table tennis had relative and significant impact on wellness of students of private secondary schools in Osun State. It indicated that physical activities involving tennis, badminton and table tennis independently had significant impact on wellness of the students. The outcome of this study was in line with the finding of Case, Fertig and Paxon (2005) that students' health is associated with low educational level, social and economic and behaviour problems.

\section{Conclusion}

It was concluded that, availability of sports facilities had significant and positive correlation with physical activity participation among students of private Secondary Schools in Osun State. Also, physical activities involving ball games of football, basketball, volleyball and handball jointly had impact on wellness of students of private secondary schools in Osun State. Conclusion was further made that football and handball had relative impact on wellness of students of private secondary schools in Osun State; while basketball and volleyball did not. In addition, physical activities involving ball games of tennis, badminton, squash and table tennis jointly had impact on wellness of students of private secondary schools in Osun State. It was concluded that, tennis, badminton and table tennis had relative impact on wellness of students of private secondary schools in Osun State; while squash did not.

\section{Recommendations}

Based on the findings of this study, the following recommendations were made:

- The Ministry of Education in Osun State should legislate that all the schools make adequate provision for sports facilities in their various schools.

- The Ministry of Education in Osun State should also ensure that all the schools, particularly the private ones are regularly monitored. This is to ensure that they conform to the regulation of the government on facilities, particularly on the provision of sporting facilities.

- School children should do daily exercises and physical activities for at least 60 minutes so as to achieve an adequate amount of physical fitness and wellness.

- There must be synergy between the Ministries of Education and Sports in order to promote development of sports among students in Osun State

\section{References}

i. Angevaren, M., Aufdemkampe, G., Verhaar, H., Aleman, A., \& Vanhees L. (2008). Physical activity and enhanced fitness to improve cognitive function in older people without known cognitive impairment. Cochrane Database of Systematic Reviews. 2.

https://www.cochranelibrary.com/cdsr/doi/10.1002/14651858.CD005381.pub3/abstract. [Accessed 12 March 2020].

ii. Best, R. J. (2010). Effects of physical activity on children's executive function: contributions of experimental. Research on aerobic exercise. Dev Rev. 30:331-551.

iii. Biddle, S.J.H., Fox, K.R., \& Boutcher, S. (2001). Physical activity and psychological well-being. London \& New York: Routledge.

iv. Biddle, S.J.H., \& Mutrie, N. (2008). Psychology of physical activity: determinants, well-being, and interventions. (2nd ed.). London: Routledge.

v. Case, A., Fertig, A., \& Paxon, C. (2005). The lasting impact of childhood health and circumstance. Journal of Health Economics 24. 365-389.

vi. Chien -Yu Pan., Chia- Hua Chu., Chia- Liang Tsai., Shen- Yu Lo., Yun- Cheng and Yu-Jen Liu. (2016). A racketsport intervention improves behavioral and cognitive performance in children with attention- deficit/ hyperactivity disorder. Research in developmental disabilities. Vol.57.110.Retrievedon 
https://www.sciencedirect.com/science/article/abs/pii/S089142221630124X?dgcid=rss_sd_all.

[Accessed $11^{\text {th }}$ January 2020].

vii. Deutsch, J. E., Borbely, M., Filler, J. Huhn., K. Guarrera-Bowlby, P. (2008). Use of a low cost, commercially available gaming console (Wii) for rehabilitation of an adolescent with cerebral palsy.Phys Ther. 88: 11961207.

viii. Dwyer, T., Coonan, W., Leitch, D., Hetzel, B., \& Baghurst, R. (1983). An investigation of the effects of daily physical activity on the health of primary school students in South Australia. International Journal of Epidemiologists, 12(3), 308-313.

ix. $\quad$ Dwyer, T., Sallis, J. F., Blizzard, L., Lazarus, R., \& Dean, K. (2001). Relation of academic performance to physical activity and fitness in Children. Pediatric Exercise Science, 13. 225-238.

X. Fahay, T.D., Insell, P.M., \& Roth, W.T, (2003). Fit and Well: core concepts and labs in physical fitness and wellness. Mountain View, California: Mayfield Publishing Company. 9.

xi. Golubovic, S., Maksimovic, J., Golubovic, B., \& Glumbic, N. (2012). Effects of exercise on physical fitnessin children with intellectual disability. Res Dev Disail. 33: 608-614.

xii. Lin, H. C., \& Wuang, Y. P. (2012). "Strength and agility training in adolescents with Down syndrome: a Randomized controlled trial. Res Dev Disabil. 33: 2236-2244.

xiii. Kuhlman, K., Lawrence J., \& Schweinhart, L.J. (1999). Timing in child development. High/Scope Educational Research Foundation. http://www.highscope.org/Research/TimingPaper/timingstudy. Html. [Accessed12 January 2020].

xiv. Leslee J. S and Debby Mitchell. (2001). Does physical activity influence academic performance? https://www.svsd.net/cms/lib01/PA01001234/Centricity/ModuleInstance/3867/PE_Learning_Article__Website.pdf. [Accessed 13 April 2020].

xv. Linder, K. J. (1999). Sport participation and perceived academic performance of school children and youth. Pediatric Exercise Science. 11. 129-144.

xvi. Linder, K. J. (2002). The Physical activity participation and academic performance relationship revisited: perceived and actual performance and the effect of banding (Academic tracking). Pediatric Exercise Science. 14, 155-170.

xvii. Ming-De Chan., Hsien-Yu Tsai., Chin-Chung Wang \& Yee-Pay Wuang (2015). The effectiveness of racket-sport intervention on visual perception and executive functions in children with mild intellectual disabilities and borderline intellectual functioning. Dove Press Journal: Neuropsychiatric Disorder and Treatment. 11. 22-94.

xviii. Nabofa, O. E \& Eboh, L.O. (2011). ICT Competency: an essential resource for physical and health education researchers in Nigeria. Edited Proceedings of the Annual International Conference of the Faculty of Education, Delta State University, Abraka 1:49-52.

xix. National Institute of Clinical Excellence. (2004). Depression: management of depression in primary and secondary care. Leicester: British Psychological Society. https://www.nice.org.uk/guidance/cg. 23. [Accessed 01 July 2020].

xx. Ofili P.C. (2010). Interfacing sports and education for optimal goal attainment. Conference proceedings of Nigeria Association of Physical, Health Education, Recreation, Sports and Dance (NAPHER-SD). Lagos.

xxi. Prist, C. (2011). Injury Risk Related to Children's Physical Activity. bjsm.bmj.com/. /bjsports-2011-09904. [Accessed 12 November 2019].

xxii. Rodrigues, S. T., Vickers, J. N., \& Williams, A. M. (2002). Head, eye and arm coordination in table tennis.nJ. Sport Sci. 20:187-200.

xxiii. Rogers, A., Furler, B. L., Brinks, S., \& Darrah, J. A. (2008). Systematic review of the effectiveness of aerobic exercise interventions for children with cerebral palsy: an AACPDM evidence report. Dev Med Child Neurol. 50:808-814.

xxiv. Shephard, R. J. (1997). Curricular physical activity and academic performance. Pediatric Exercise Science. 9:113-125.

xxv. Taylor, L. M., Maddison, R., Pfaeffi, L.A., Rawstorm, J. C., Gant, N. \& Kerse, N. M. (2012). Activity and energy expenditure in older people playing active video games. Arch Phys Med Rehabil. 93:2281-2286.

xxvi. The United Nations Convention on the Rights of the Child, (1989). http://www.google.com.ng/search?hl. [Accessed 13 October 2016].

xxvii. Thornton, L. E., Pearce, J. R., \& Kavanagh, A. M. (2011). Using geographic information systems (GIS) to access the role of the built environment in influencing obesity: a glossary. Int J Behav Nutr Phys Act. 8:71.

xxviii. Tremblay, M. S., Inman, J. W., \& Williams, J. D. (2000). The Relationship between physical activity, self-esteem, and academic achievement in 12-Year-Old Children. Pediatric Exercise Science. 12, 312-324.

xxix. Tsai, C. L. (2009). The effectiveness of exercise intervention on inhibitory control in children with developmental coordination disorder: using a visuo-spatial attention paradigm as a model. Res Dev Disabil. 30 (6) :1269-1280.

xxx. United Nations Convention on the Rights of the Child (UNCRC). (2016). http://www.unicef.org.uk/UNICEFsWork/UN-Convention. (2016). [Accessed 12 August 2019].

xxxi. Watson, J. (2010). Interscholastic sports. www. SEP_271-interscholarstic_sports_12-24-02.com. Nov-Dec 2009: 30 (6): 1268-80. Doi:10.1016/j.ridd. 2009.05.001. [Accessed 14 March 2020]. 
xxxii. World Health organization, WHO. (2004). The 2004 World Health Report 2004. https://www.google.com/search?q=The+2004+World+Health+Report+2004\%2Cpdf\&ie=utf-8\&oe=utf8\&client=firefox-b. [Accessed 14 February 2020].

xxxiii. Wuang, Y. P., Chiang, C. S., Su, C. Y., \& Wang, C. C. (2011). Effectiveness of virtual reality using Wiigaming Technology in children with Down syndrome. Res Dev Disabil. 32 (1):312-321. https://pubmed.ncbi.nlm.nih.gov/21071171/. [Accessed 12 June 2020]. 